\title{
Margaret McCartney: Medicine must do better on gender
}

\author{
Margaret McCartney general practitioner
}

Glasgow

\begin{abstract}
Medicine has a shameful history when it comes to sex, gender, and identity. Attempts have been made to "fix" sex, for example, by intervening surgically to "normalise" the genital appearances of intersex people. This happened despite a lack of evidence of benefit and showed disregard for individuals' feelings over time ${ }^{12}$-including a lack of full information about their own condition or support, especially regarding fertility. Even well intentioned medicine can do grievous harm.
\end{abstract}

In recent years terms such as "non-binary" and "gender fluid" have entered the mainstream. The Office for National Statistics may make declaration of sex voluntary in the 2021 census, out of concern that it discriminates against and offends transgender people. ${ }^{3}$ NHS IT systems don't respond flexibly: for example, transgender men may still wish to be invited for cervical screening. The Gender Identity Bill, currently in consultation, would allow people legally to self declare their gender rather than, as now, being required to live as their preferred gender for two years and have a medical diagnosis of gender dysphoria before it's granted.

And a clear rise in referrals of children to specialist gender identity services has been seen in recent years, particularly in teens. ${ }^{4}$ Yet the role assigned to medicine can't be separated from societal attitudes and abilities. The debate on gender occurs in an environment where boys are seen as being boys, and girls as girls, because of how they behave rather than their biological sex.

Frequently, media narratives describing parents' realisation that their child may be transgender occurs when the preschool child is interested in doing or wearing things outside society's expectations. Yet playing with dolls and liking dresses doesn't make children female, just as playing with trucks and liking mud doesn't make them male.

Therapists are right to be concerned about overdiagnosis and overtreatment. But this concern can be perceived by parents as a barrier rather than a caring, evidence based response.

Many children with gender dysphoria will grow up without reassignment surgery but will be gay or bisexual. ${ }^{56}$ One concern is that gender reassignment makes homosexuality "disappear": in Iran being gay is illegal, but the rate of gender reassignment surgery is the highest in the world.

Therapists are right to be concerned about overdiagnosis and overtreatment, but this concern can be perceived by parents as a barrier

In some people, gender reassignment is clearly beneficial but prognostication can be complicated by missing data, ${ }^{8}$ surgical complications, ${ }^{910}$ and-at least in previous cohorts-higher levels of associated psychiatric morbidity than in the general population. ${ }^{11}$ Insensitivity hurts; treatments have side effects; and suicide, tragically, has been the result for some people with gender dysphoria who have not been adequately supported. No blood test or brain scan can tell which person with gender dysphoria will do better or worse with the medical and irreversible surgical treatments on offer.

We need better long term data, but research into rates of de-transition has been stymied by ethics committees apparently more concerned about controversy than helping people to make good decisions. ${ }^{12}$ This doesn't help anyone. The need to treat women and men differently has usually been for reasons of biology and fairness-from sports competitions to access to rape crisis shelters and within the criminal justice system. And clearly, trans people would have particular risks if held in a prison of the gender of their birth sex, just as women would if incarcerated with a male bodied person convicted of sexual assault who identifies as female.

Respectful, calm debate is necessary. How society and medicine deal with gender requires critical review in terms of the potential for unintended harms, even if there are no easy answers.

Competing interests: See www.bmj.com/about-bmj/freelance-contributors/margaretmccartney.

Provenance and peer review: Commissioned; not externally peer reviewed.

Follow Margaret on Twitter, @mgtmccartney

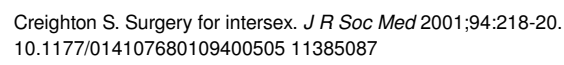


3 Office for National Statistics. Qualitative research on gender identity: phase 1 summary report. Sept 2017. https://www.ons.gov.uk/methodology/classificationsandstandards/ measuringequality/genderidentity/

qualitativeresearchongenderidentityphase1 summaryreport\#executive-summary.

Tavistock and Portman NHS. GIDS referrals increase slows in 2016-17. 27 April 2017. http://bit.ly/2u9UC5S

5 Korte A, Lehmkuhl U, Goecker D, Beier KM, Krude H, Grüters-Kieslich A. Gender identity disorders in childhood and adolescence: currently debated concepts and treatment strategies. Dtsch Arztebl Int 2008:105:834-41. 10.3238/arztebl.2008.0834. 19578420

6 Wallien MS, Cohen-Kettenis PT. Psychosexual outcome of gender-dysphoric children. J Am Acad Child Adolesc Psychiatry 2008;47:1413-23.

10.1097/CHI.0b013e31818956b9 18981931

7 Tait R. Sex changes and a draconian legal code: gay life in Iran. Guardian 25 Sept 2007. https://www.theguardian.com/world/2007/sep/25/iran.roberttait.

8 Hess J, Rossi Neto R, Panic L, Rübben H, Senf W. Satisfaction with male-to-female gender reassignment surgery. Dtsch Arztebl Int 2014;111:795-801. 10.3238/arztebl.2014.0795. 25487762
9 Dreher PC, Edwards D, Hager S, etal . Complications of the neovagina in male-to-female transgender surgery: a systematic review and meta-analysis with discussion of management. Clin Anat 2018:31:191-9. 10.1002/ca.23001 29057562

10 Raigosa M, Avvedimento S, Yoon TS, Cruz-Gimeno J, Rodriguez G, Fontdevila J. Male-to-female genital reassignment surgery: a retrospective review of surgical technique and complications in 60 patients. J Sex Med 2015;12:1837-45. 10.1111/jsm.12936 26139337

11 Dhejne C, Lichtenstein $\mathrm{P}$, Boman M, Johansson $\mathrm{AL}$, Långström N, Landén M. Long-term follow-up of transsexual persons undergoing sex reassignment surgery: cohort study in Sweden. PLoS One 2011;6:e16885. 10.1371/journal.pone.0016885 21364939

12 Caspian J. Free speech matters. https://www.crowdjustice.com/case/free-speech-mattersround2/.

Published by the BMJ Publishing Group Limited. For permission to use (where not already granted under a licence) please go to http://group.bmj.com/group/rights-licensing/ permissions 